\title{
Anti-fungal activity of Carica papaya leaf extract against candida albicans and its synergy with fluconazole: an in-vitro study
}

\author{
Nilofer Noorie M.*, Chenthamarai G.
}

Department of Pharmacology, Government Kilpauk Medical College, Tamil Nadu, India

Received: 17 November 2020

Accepted: 16 December 2020

*Correspondence:

Dr. Nilofer Noorie M.,

Email: nilofer.m.noorie@gmail.com

Copyright: ( $\odot$ the author(s), publisher and licensee Medip Academy. This is an open-access article distributed under the terms of the Creative Commons Attribution Non-Commercial License, which permits unrestricted non-commercial use, distribution, and reproduction in any medium, provided the original work is properly cited.

\begin{abstract}
Background: In this study objectives were to evaluate the antifungal activity in increasing concentrations of ethanolic extract and aqueous extract of Carica papaya against Candida albicans and to assess the synergistic activity of ethanolic extract of Caricia papaya with flucanazole as a potential antifungal.

Methods: The aim of the study was to evaluate the antifungal activity in increasing concentrations, $500 \mu 1 / \mathrm{ml}, 750$ $\mu \mathrm{l} / \mathrm{ml}$ and $1000 \mu \mathrm{l} / \mathrm{ml}$ of ethanolic extract and aqueous extract of caricia papaya against Candida albicans and the synergistic activity with Fluconazole was assessed by observing the zone of inhibition in agar disc diffusion assay and by observing the turbidity in minimum inhibitory concentration (MIC) assay.

Results: It was observed that ethanolic extract of Carica papaya leaf showed significant antifungal activity in higher concentration of $1000 \mu \mathrm{g} / \mathrm{ml}$ with zone diameter of $11.97 \pm 0.15 \mathrm{~mm}$ in disc diffusion assay and MIC of $350 \mu \mathrm{g} / \mathrm{ml}$. The ethanolic extract of Carica papaya leaf with fluconazole showed synergistic activity with zone diameter of $13.6 \pm 0.45$ $\mathrm{mm}$ in disc diffusion assay and MIC was $125 \mu \mathrm{g} / \mathrm{ml}$, whereas the standard drug Fluconazole's zone of inhibiton was $12.83 \pm 0.9$ in disc diffusion and MIC was $500 \mu \mathrm{g} / \mathrm{ml}$.

Conclusions: From this study, we can safely conclude that the Carica papaya leaf extract has a significant antifungal property and exhibit synergistic effect when used with fluconazole.
\end{abstract}

Keywords: Carica papaya leaf, Synergism, Candida albicans

\section{INTRODUCTION}

Carica papaya, belongs to the family of Caricaceae, and several species of Caricaceae have been used as remedy against a variety of diseases. ${ }^{1}$ The leaves of papaya have been shown to contain many active components that can increase the total antioxidant power in blood and reduce lipid peroxidation level, such as papain, chymopapain, cystatin, tocopherol, ascorbic acid, flavonoids, cyanogenic glucosides and glucosinolates. ${ }^{2}$ Plants with activity against human pathogenic fungi are of interest because of emerging resistance to present treatment. ${ }^{3}$ The infections caused by fungi are recognized as a recent emerging danger to public health. ${ }^{4}$ Numerous researches on epidemiology of fungal infections reveal that the prevalence and incidence of fungal infection is a major public health concern. Recent years show increase in the treatment failures due to prolonged use of the antifungal drugs and also due to increase in population of immunecompromised such as HIV patients, organ transplant patients and cancer chemotherapy patients. ${ }^{5}$ Candida is an opportunistic commensal of the human oral, gastrointestinal, vaginal, cutaneous and mucosal surfaces. ${ }^{6}$ Candida albicans is the predominant causative organism of virtually all types of candidiasis. ${ }^{7}$ The current therapy available for fungal infections are insufficient as they are ineffective against new or remerging fungi which leads to the rapid development of resistance. For a long time, Azoles have been a predominant therapy for candida infections. Fluconazole is the commonly used azole for systemic candidiasis due to its wide tissue distribution, high solubility and low toxicity. ${ }^{8}$ Efficacy of fluconazole 
and other antifungals can be improved with combination therapy and newer therapeutic strategies are needed to overcome the major issue with the available treatment. ${ }^{9,10}$

\section{Aim and objectives}

Aim and objectives were to evaluate the antifungal activity in increasing concentrations of ethanolic extract and aqueous extract of Caricia papaya against Candida albicans and to assess the synergistic activity of ethanolic extract of Caricia papaya with flucanazole as a potential antifungal.

\section{METHODS}

\section{Preparation of plant extract}

The fresh leaves of Caricia papaya were procured from the local nursery. The samples were washed, sun dried and made into a powder. The leaves of Caricia papaya were extracted with solvent of aqueous and $70 \%$ ethanol. The containers were kept in the dark for 3-5 hours. Then the solutions were filtered and left in hot air oven at $50^{\circ} \mathrm{c}$ till the extract got dried. The dried extracts were dissolved in dimethylsulfoxide, making extracts of different concentrations.

\section{Pathogens}

The fungal pathogens (Candida albicans) available with LIFETEK research centre were sub cultured and used in the study.

\section{Preparation of the media}

Sabouraud dextrose agar was used to culture Candia albicans. Loops full of fungal culture was inoculated in the Sabouraud dextrose agar medium and incubated for 72 hours at room temperature.

\section{Assessment of anti-fungal properties}

\section{Agar disc diffusion method}

Antifungal activity of the sample was determined by disc diffusion method on sabouraud dextrose agar (SDA) medium. Sabouraud dextrose agar (SDA) medium was poured in to the petriplate. After the medium was solidified, the inoculums were spread on the solid plates with sterile swab moistened with the fungal suspension.
Fluconazole $(15 \mathrm{mg})$ is taken as positive control. The extracts and positive control of $20 \mu \mathrm{l}$ each were added in sterile discs with each disc containing increasing concentrations as $500 \mu \mathrm{g} / \mathrm{ml}, 750 \mu \mathrm{g} / \mathrm{ml}$ and $1000 \mu \mathrm{g} / \mathrm{ml}$ and placed in SDA plates. The plates were incubated at $28^{\circ} \mathrm{c}$ for $24 \mathrm{hrs}$. After the initial culture of the extracts, to assess the synergistic activity the fixed combination of Carica papaya leaf extract and flucanazole were used and cultured again. The antifungal activity was determined by measuring the diameter of zone of inhibition ( $\mathrm{mm}$ ) around the disk, which was measured by vernier caliper.

\section{Minimum inhibitory concentration assay (MIC)}

\section{Sample preparation}

One mg of plant extract powder was taken and mixed with $1 \mathrm{ml}$ of DMSO obtaining the concentration of $1 \mathrm{mg} / \mathrm{ml}$

\section{MIC determination:}

This assay determines the studied agent's capability to inhibit the growth of known micro-organism. Minimum Inhibitory concentration is achieved by passing the sample through the method of successive dilution.

One $\mathrm{ml}$ of sterile potato dextrose agar broth was distributed to 8 tubes and was submitted to autoclave under constant pressure at the temperature of $121^{\circ} \mathrm{c}$. After the broth reaches room temperature, $1 \mathrm{ml}$ of diluted sample was added in tube1. Then $1 \mathrm{ml}$ was transferred from tube 1 to tube 2. This transfer was repeated successively until it reaches tube $8.100 \mu$ of Candida albicans cultures were added to all the tubes from 1 to 8 . Incubation was done at $37^{\circ} \mathrm{C}$ for $24 \mathrm{hrs}$. After incubation, the turbidity was observed. MIC, the concentration of higher dilution tubes in which the absence of fungal growth occurred, were noted.

\section{RESULTS}

\section{Agar disc diffusion method}

As evident from (Figure 1 to 4 ) and summarised in (Table 1). The antifungal activity was not demonstrated with aqueous extract of papaya leaf extract with increasing concentrations. In ethanolic extract of plant, demonstrated the antifungal activity against Candida albicans, of which highest concentration showed significant activity with zone diameter of $11.97 \pm 0.15 \mathrm{~mm}$ (Table 1$)$.

Table 1: Zone of inhibitons of test and standard drug.

\begin{tabular}{|llllll|}
\hline S. no. & Test & \multicolumn{2}{l}{ Zone of inhibition $(\mathbf{m m})(\mathbf{M e a n} \pm \mathrm{SD})$} & \\
\hline $\mathbf{1}$ & Papaya leaf ethanol extract & $11.97 \pm 0.15$ & $9.7 \pm 0.7$ & $8.73 \pm 0.59$ & $12.93 \pm 0.66$ \\
$\mathbf{2}$ & $\begin{array}{l}\text { Papaya leaf ethanol extract } \\
\text { + Fluconazole }\end{array}$ & $13.6 \pm 0.45$ & $9.3 \pm 0.56$ & $8.2 \pm 0.60$ & $12.83 \pm 0.95$ \\
\hline $\mathbf{3}$ & $\begin{array}{l}\text { Papaya leaf aqueous extract } \\
\text { Pat }\end{array}$ & - & - & - & $14 \pm 0.3$ \\
\hline
\end{tabular}




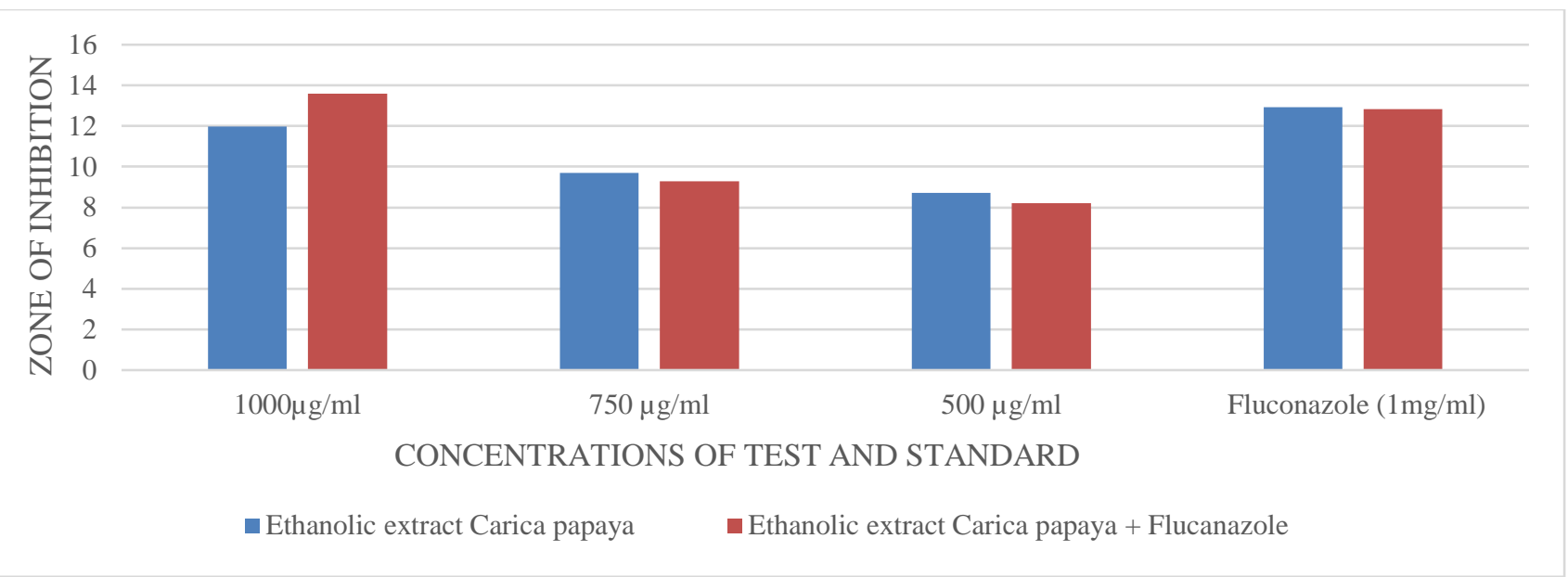

Figure 1: Comparing the zone of inhibition of ethanoolic Carica papaya leaf extract and ethanolic Carica papaya leaf with fluconazole.

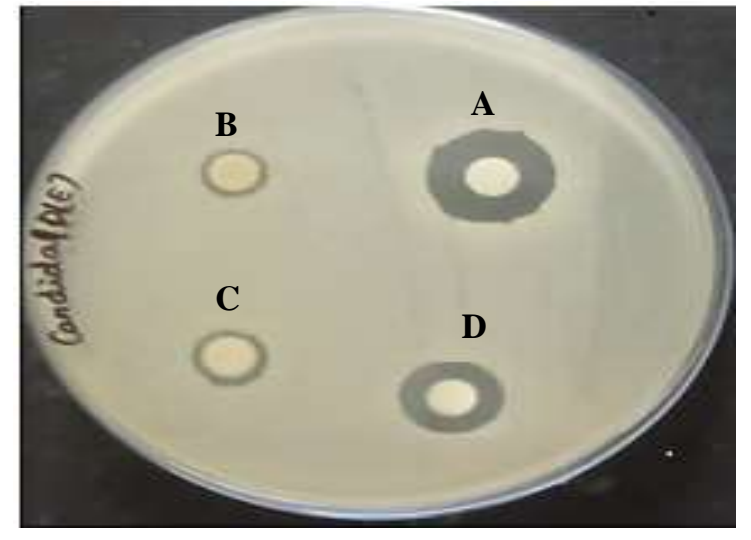

Figure 2: The zone of inhibition of ethanolic extract of Carica papaya leaf in diffrent concentrations. AFluconazole, B-500 $\mu \mathrm{g} / \mathrm{ml}$ of ethanolic plant extract, C$750 \mu \mathrm{g} / \mathrm{ml}$ of ethanolic plant extract, D- $1000 \mu \mathrm{g} / \mathrm{ml}$ of ethanolic plant extract.

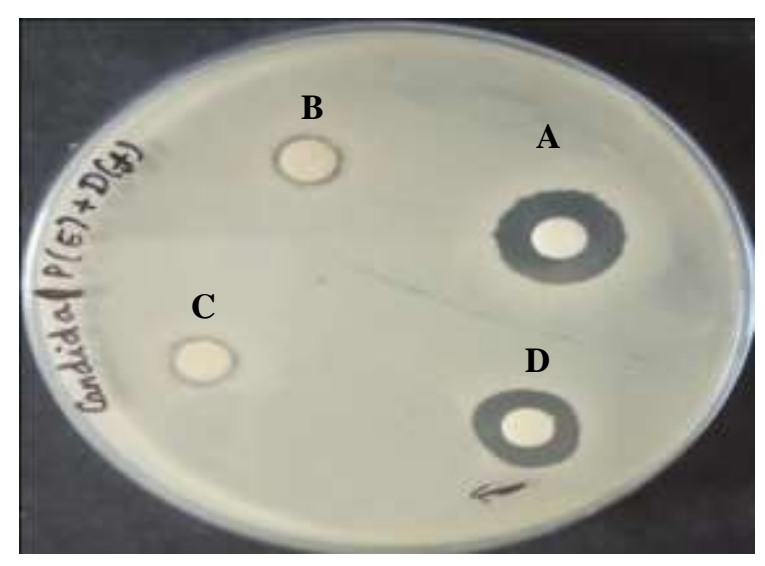

Figure 3: The zone of inhibition of ethanolic extract of Carica papaya leaf + Fluconazole in diffrent concentrations. A- Fluconazole, B-500 $\mu \mathrm{g} / \mathrm{ml}$ of ethanolic plant extract+ Fluconazole, $C-750 \mu \mathrm{g} / \mathrm{ml}$ of ethanolic plant extract+ Fluconazole, D- $1000 \mu \mathrm{g} / \mathrm{ml}$ of ethanolic plant extract+ Fluconazole.
The synergistic activity with Fluconazole and plant extract showed highly significant antifungal activity with zone of inhibition of $13.6 \pm 0.45 \mathrm{~mm}$ when compared with the standard drug (fluconazole) (Figure 3).

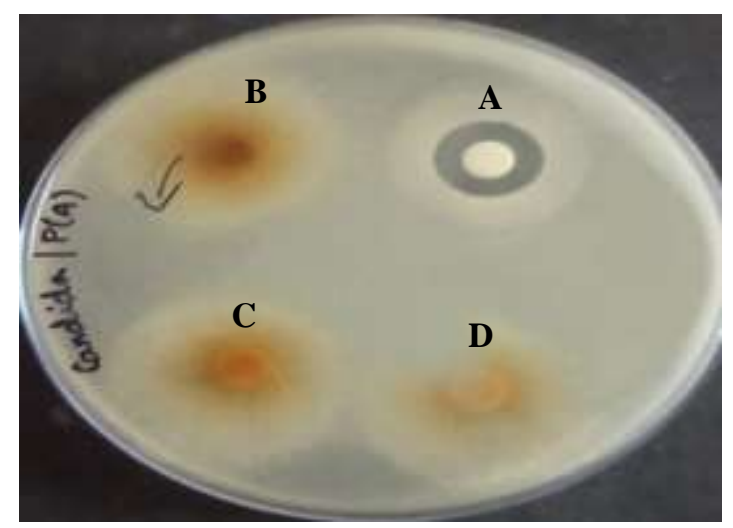

Figure 4: The zone of inhibition of aqeous extract of Carica papaya leaf. A- Fluconazole, B-500 $\mu \mathrm{g} / \mathrm{ml}$ of aqeous plant extract, $\mathrm{C}-\mathbf{- 7 5 0} \mu \mathrm{g} / \mathrm{ml}$ of aqeous plant extract, D- $1000 \mu \mathrm{g} / \mathrm{ml}$ of aqeous plant extract.

Table 2: Minimum inhibitory concentrations of test and standard.

\begin{tabular}{|lll|}
\hline S. no. & Sample & $\begin{array}{l}\text { Minimum inhibitory } \\
\text { concentration }(\boldsymbol{\mu g} / \mathrm{ml})\end{array}$ \\
\hline 1. & Fluconazole (drug) & 500 \\
\hline 2. & $\begin{array}{l}\text { Papaya leaf ethanol } \\
\text { extract }\end{array}$ & 350 \\
\hline $\mathbf{3}$ & $\begin{array}{l}\text { Papaya leaf ethanol } \\
\text { extract+Fluconazole }\end{array}$ \\
\hline $\mathbf{4}$ & $\begin{array}{l}\text { Papaya leaf aqueous } \\
\text { extract }\end{array}$ \\
\hline
\end{tabular}

\section{Minimum inhibitory concentration}

In this test, the plant extract showed moderate antifungal activity with MIC of $250 \mu \mathrm{g} / \mathrm{ml}$ when compared to the 
control. This test also demonstrated the synergistic activity of the antifungal property of the extract with MIC of 125 $\mu \mathrm{g} / \mathrm{ml}$ (Table 2). The aqueous extract did not show any activity.

\section{DISCUSSION}

Recent years emphasize the need for antifungal agent in the current situation to overcome the eminent crisis due to increased incidence of resistance and antifungal treatment failures. The major causative factor for the development of this crisis owes largely to increase in the immune compromised population and need for prolonged therapy in situations such as HIV patients, organ transplantation and cancer chemotherapy. ${ }^{5}$

In this current study, the antifungal activity of the papaya leaf ethanolic extract was clearly demonstrated in all concentrations, when compared to standard. This result was seen in both disc diffusion assay and minimum inhibitory concentration which was in agreement to a study in which revealed that the papaya leaf extract exhibited antifungal property in well diffusion method. ${ }^{11}$ Our study showed that the concentration of ethanolic extract effectively suppresses the mycelia growth of Candida albicans and this effect was found to increase with concentration of ethanolic extract. Although, synergistic activity of the Carica papaya leaf extract with the standard drug Fluconazole has not been studied previously. The current study reveals that the papaya leaf extract markedly reduces the MIC, which indicates that the minimum amount of the test components is needed to inhibit the Candida growth, when used along with Fluconazole. Also, the zone diameter was increased when used in combination, stipulating increased sensitivity of the organism to the test compound when compared to the individual plant extracts. Considering these results, there is a strong synergistic antifungal activity between ethanolic papaya leaf extract and fluconazole.

The phytochemical constituent of the medicinal plants plays a major role in its therapeutic potential. In a study the phytochemical components of Carica papaya have been studied and they showed many active principles such as alkaloids, carbohydrates, saponins, glycosides, proteins and aminoacids, phytosterol, flavinoids, terpinoids and tannins in various extracts. This study also showed that the ethanolic extract contained all the active principles found in the plant extract but the aqueous plant extract showed only alkaloids. ${ }^{12}$ In our study, this may attribute to no activity of aqueous plant extract and presence significant antifungal activity in ethanolic plant extract. Also, it may be safe to conclude that the increasing activity with increasing concentrations may be due to the presence of more amount of active principle in higher concentration of the ethanolic extract of Carica papaya. However, further research is needed to unveil the mechanism of action and the specific active component of the extract contributing to the antifungal activity.
From this study, we found that the Carica papaya leaf extract has an antifungal activity and has synergistic effect when used with fluconazole. Further, in-vivo studies with other fungi will assess the potential use of these compounds for extended therapeutic applications.

\section{CONCLUSION}

From this study, we can safely conclude that the Carica papaya leaf extract has a significant antifungal property and exhibit synergistic effect when used with fluconazole. Therefore, this can be considered as a potential agent against human pathogenic fungi in future after meticulous research. This preliminary study was an attempt with positive results and a bridge for future research to develop a potential agent to overcome the emerging public health crisis.

\section{ACKNOWLEDGEMENTS}

I heartily thank Dr. I. Seethalakshmi, Director Life Tek research centre for technical support during the experiment.

\section{Funding: No funding sources Conflict of interest: None declared \\ Ethical approval: The study was approved by the Institutional Ethics Committee}

\section{REFERENCES}

1. Mello VJ, Gomes MT, Lemos FO, Delfino JL, Andrade SP, Lopes MT, et al. The gastric ulcer protective and healing role of cysteine proteinases from Carica candamarcensis. Phytomedicine. 2008;15237-44.

2. Otsuki N, Dang NH, Kumagai E, Kondo A, Iwata S, Morimoto C. Aqueous extract of Carica papaya leaves exhibits anti-tumor activity and immunomodulatory effects. J Ethnopharmacol. 2010;127(3):760-7.

3. Sugar AM, Alsip SG, Galgiani JN, Graybill JR, Dismukes WE, Claud GA, et al. Pharmacology and toxicity of high-dose ketoconazole. Antimicrob Agent Chemother. 1987;31:1874-8.

4. Wu TC. On the development of antifungal agents: perspective of the US Food and Drug Administration. Clin Infect Dis. 1994;19:S54-8.

5. Walsh TJ, Gonzalez C, Lyman CA, Chanock SJ, Pizzo PA. Invasive fungal infections in children:recent advances in diagnosis and treatment. Adv Pediatr Infect Dis. 1996;11:187-290.

6. 6. Eggimann, P., Garbino, J. \& Pitte, D. (2003). Epidemiology of Candida species infections in critically ill non-immunosuppressed patients. Lancet Infect Dis 3, 685-702.

7. Filler SG, Sheppard DC. Fungal invasion of normally non-phagocytic host cells. PLoS Pathog. 200629;2(12):e129.

8. Brammer KW, Farrow PR, Faulkner JK. Pharmacokinetics and tissue penetration of 
fluconazole in humans. Rev Infect Disea. 1990;12(3):S318-26.

9. Pinto E, Vale-Silva L, Cavaleiro C, Salgueiro L. Antifungal activity of the clove essential oil from Syzygium aromaticum on Candida, Aspergillus and dermatophyte species. J Med Microbiol. 2009;58(11):1454-62.

10. Ghannoum MA, Fu Y, Ibrahim AS, Mortara LA, Shafiq MC, Edwards JE, et al. In vitro determination of optimal antifungal combinations against Cryptococcus neoformans and Candida albicans. Antimicrob Agents Chemother. 1995;39(11):2459-65.
11. Khan JA, Yadav J, Srivastava Y, Pal PK. In vitro evaluation of antimicrobial properties of Carica papaya. Int J Biol, Pharm Alli Sci. 2012;1(7):933-45.

12. Baskaran C, Velu S, Kumaran K. The efficacy of Carica papaya leaf extract on some bacterial and a fungal strain by well diffusion method. Asia Pacif J Tropic Dise. 2012;2:S658-62.

Cite this article as: Nilofer NM, Chenthamarai G. Anti-fungal activity of Carica papaya leaf extract against candida albicans and its synergy with fluconazole: an in-vitro study. Int J Basic Clin Pharmacol 2021;10:101-5. 